by the long-continued local application of potent steroids. It is known that the psoriatic skin may absorb many times more readily than normal; and that under polyethylene occlusion this is further greatly enhanced.

The association is difficult to prove, but clinical observation suggests that some patients with extensive psoriasis are subject to striking relapse, unexpected deterioration, and to the first development of pustules in relation to local steroid application or its cessation. It is, I believe, open to question whether the application of steroids to extensive cases is wise, particularly if this is continued over long (months) periods and especially if combined with polyethylene occlusion. Beyond a comparatively slight symptomatic improvement this form of treatment gives rather little benefit to most psoriasis sufferers. I suggest that it also exposes them to a risk of serious aggravation. -I am, etc.,

F. RAy Bettley

London $\mathrm{W} .1$

1 Ryan, T. J., and Baker, H., British fournal of Dermatology, 1971, 85, 407

SIR,-In the leading article "Generalized Pustular Psoriasis" (29 January, p. 262) you quote Ryan and Baker's findings ${ }^{1}$ that death in this condition may be due to the disease or its treatment with systemic corticosteroid or methotrexate.

Severe or extensive psoriasis is now treated by many with topical steroids under polyethylene occlusion. Rebound of the psoriasis with pustulation may occur when the use of steroids topically or systemically is curtailed for various reasons even when the psoriasis has been controlled. The same sequence may be observed when treatment is given with methotrexate. The use of these potent preparations for the treatment of psoriasis may be hazardous.

T. McFadyen and A. Lyell ${ }^{2}$ have rendered a service when they demonstrated a concealed bacteraemia in patients receiving steroids or methotrexate in whom the ordinary clinical signs of systemic infection would be suppressed. In fact it is known that low grade bacteraemia may occur in any exfoliative dermatitis, whatever the cause, by invasion through the skin and there was less difficulty in the diagnosis of this complication in presteroid days.

The paragraph in the leading article on the "flaccidity" of the definition of an "ide" eruption was indeed flaccid. Dermatologists have a reasonable conception of the aetiology and morphology of "ides" of the skin.-I am, etc.,

London N.W.1

LOUIS FORMAN

1 Ryan, T. J., and Baker, H., British fournal of Dermatology, 1971, 85, 407.
McFadyen, T., and Lyell, A., British fournal
of Dermatology, 1971, 85, 274.

\section{Controlled Trial of Penfluridol in Acute Psychosis}

SIR,-The need for long-acting forms of medication in the extended care of schizophrenic patients is now well established and I was interested to read the report by Dr. H. M. van Praag and others (18 December, p. 710) on a new oral compound of this type. However, I am very puzzled by their conclusion that "oral medication has the advantage of being much more manageable for 'field workers' (social psychiatrists and practitioners)."

Firstly, what do they mean by "social psychiatrists?" If these doctors are working in hospitals or clinics they are surely not going to find periodic injections very difficult, particularly if nurses are working alongside them. So far as domiciliary work is concerned, it is unlikely that any psychiatrist will visit a patient weekly to see that he takes a tablet, and on an initial consultation something more effective than one dose of penfluridol is likely to be needed.

Secondly, what is the advantage to general practitioners? If the doctor is seeing the patient weekly the difficulty of giving an injection is surely minimal, whereas the advantages of intramuscular medication are considerable. ${ }^{1}$ However, such frequent contact is unlikely to be possible over the long periods necessary in treating many schizophrenic patients, and I hope that the Dutch authors are not suggesting that treatment should be undertaken without psychiatric consultation at any stage. In a condition as serious as schizophrenia this would surely be unwise in any area where a psychiatrist is available.

But if the patient is not seen actually swallowing the tablet each week by a professional worker (and even this sight can sometimes be misleading), we are back where we started in the days of ineffective, unreliable oral medication. Quite apart from any "magic "charge' of the syringe," an injection leaves no doubt as to whether the patient has received the medication or not. Also, recent absorption studies ${ }^{2}$ indicate that this is generally by far the most efficacious route. Our studies in Salford ${ }^{3}$ show that fluphenazine decanoate injections can substantially reduce the amount of time that a large sample of schizophrenic patients need to spend in hospital, when other conditions are held as constant as possible. I remain to be convinced that this regimen is less "manageable" than that proposed with oral penfluridol.-I am, etc.,

Hope Hospital,

Hugh FreemaN

1 Freeman, H. L., Fournal of Specialist Medicine: Psychiatry and Neurology, 1971, 2, 3. Curry, S. H., Davis, J. M., Janowsky, D. S., and
Marshall, J. H. L., Archives of General Marshall, J. H. L., Archives of General Johnson, D. A. W., and
Practitioner, 1972, in press.

\section{Psychosis and Ketamine}

SIR,-I should like to support the suggestion of Drs. S. M. Laird and M. Sage (22 January, p. 246) that adequate preoperative sedation will do much to prevent the dreams and restlessness associated with the recovery of consciousness in adults after ketamine anaesthesia. I have completed a study of 100 patients between the ages of 17 and 47 years who required surgical operations of a relatively minor nature. Each patient received nitrazepam $10 \mathrm{mg}$ and droperidol $20 \mathrm{mg}$ orally about 1 hour preoperatively. This mixture provides excellent sedation and sleep in virtually all patients not afflicted with pain.1 Anaesthesia was induced in each patient with an average dose of ketamine $250 \mathrm{mg}$ intravenously and maintained with supplementary doses of ketamine $100 \mathrm{mg}$ intravenously at approximately 10 minute intervals. Inhalational agents were not used. Twenty-five of the patients were also curarized, intubated, and ventilated with air or oxygen during operations on pelvic viscera, mainly hysterotomy, partial salpingectomy, or appendicectomy.

Careful postoperative interrogation of each patient by members of the nursing and surgical staffs revealed that all patients were fully anaesthetized during the period of surgery, and none experienced dreams or other unpleasantness. The nitrazepamdroperidol premedication completely suppressed the dreams and mental agitation associated with the recovery from ketamine anaesthesia in adults, and no special precautions were required to maintain silence and the lack of other disturbances during recovery. The premedication also prevented the muscular catatonia or rigidity which sometimes complicates ketamine anaesthesia. Full details of the study will be reported elsewhere. ${ }^{2}$-I am, etc.,

Royal Infirmary,

M. JOHNSTONE

Manchester

1 Johnstone, M., British fournal of Anaesthesia, $1971,43,380$.

(Australia), in Anaesthesia and Intensive Care

SIR,-Drs. S. M. Laird and M. Sage (22 January, p. 246) are almost certainly correct in contending that ketamine is not contraindicated in psychiatric patients. Because of the advantages of an intramuscular anaesthetic in certain situations, we recently made a study ${ }^{1}$ of ketamine anaesthesia in electroconvulsion therapy, together with Dr. Sara Hereward of the department of anaesthesia, University of the West Indies.

In over 60 ketamine anaesthetics given to depressed and/or psychotic patients, hallucinations and other unpleasant emergence phenomena did not occur, and this supports the findings of Orecchia et $a l^{2}{ }^{2}$ in a larger series using only the intravenous route. However, as most candidates for E.C.T. are concurrently receiving one or more psychotropic drugs, it is not clear whether it is the E.C.T. or the medication-or both-which provide this "protection."

We saw nothing to suggest that ketamine had any adverse long-term effect on the psyche in our patients. Albin and Dresner ${ }^{3}$ have already shown that no such effects appear to follow its use in non-psychiatric patients.

In addition to causing no cardiac depression, little or no respiratory depression, and minimal interference with the airway, intramuscular ketamine in a dose of $4.4 \mathrm{mg}$ / $\mathrm{kg}$ gives a pleasant and rapid inductionusually within three minutes when mixed with hyaluronidase. It can with advantage be given by a nurse known to the patient, avoiding the anxiety which some patients feel when exposed to strange faces and sinister-looking apparatus. In the absence of hypertension, we regard it as the anaesthetic of choice for E.C.T. where the patient is anxious and disturbed, or has no visible veins. - We are, etc.,

Midland Nerve Hospital,

COLIN BREWER Birmingham

Royal Edinburgh Hospital,

JoNathan Davidson Edinburgh 1 Brewer, C., Hereward, S., and Davidson, J. R. T., 2 Orecchia, C., Marullo-Reedtz, G., and Bram, S. Minerva Anestesiologica, 1969, 35, 711 . Albin, M. S., and Dresner, A. J., paper delivered to International Symposium, Ostend, 1969. 